\title{
New Indicator of Inflammation in Migraine: Red Blood Cell Distribution
}

\author{
Zeynep Bastuğ Gül1 , Rabia Gökçen Gözübatık Çelik¹, (i) Batuhan Selçuk ${ }^{1}$, (i) Sena Aksoy ${ }^{1}$, \\ Mehmet Gül' ${ }^{2}$, $\odot$ Aysun Soysal ${ }^{1}$ \\ ${ }^{1}$ Department of Neurology, University of Health Sciences Turkey, Bakirkoy Prof. Dr. Mazhar Osman Training and Research Hospital for \\ Psychiatric, Neurologic and Neurosurgical Diseases, Istanbul, Turkey \\ ${ }^{2}$ Department of Cardiology, University of Health Sciences Turkey, Istanbul Mehmet Akif Ersoy Thoracic and Cardiovascular Surgery \\ Training and Research Hospital, Istanbul, Turkey
}

\begin{abstract}
Introduction: The role of inflammation in the pathophysiology of migraine is controversial. We aimed to investigate new inflammatory markers such as red blood cell distribution width (RDW) and plateletcrit in patients with migraine.

Methods: In this study, 100 patients suffering from migraine and 67 healthy controls with similar demographic characteristics were included in the study. Complete blood count (CBC) including number of neutrophils, lymphocytes and platelets, RDW, plateletcrit, erythrocyte sedimentation rate (ESR), C-reactive protein (CRP), fasting blood glucose, serum creatinine, and neutrophil-to-lymphocyte ratio (NLR) was compared between these two groups. SPSS was used for statistical analysis. Results: There was positive correlation between RDW and migraine group, CRP, plateletcrit, platelet, and neutrophil counts. The results of ESR, platelet count and RDW in migraine group were higher than control group significantly $(p=0.044, p=0.024$, and $p=0.002$, respectively). CRP, NLR, and plateletcrit were higher in migraine group without significance. In multivariate analysis, RDW was found as a significant independent predictor of migraine after adjusting for other risk factors ( $p=0.048)$. In a receiver operating characteristic curve analysis, an RDW value of $13.25 \%$ was identified as an effective cutoff point for migraine (area under curve $=0.620,95 \%$ confidence interval: $0.53-0.71, p=0.009$ ). An RDW value of more than $13.25 \%$ yielded a sensitivity of $58 \%$ and a specificity of $54 \%$.

Discussion and Conclusion: In our study, we found that RDW was higher in patients with migraine than control group, independent of other variables. RDW can be used as an inflammatory marker for migraine with a simple and inexpensive CB examination.

Keywords: C-reactive protein; inflammation; migraine disorders
\end{abstract}

$\mathrm{T}_{\mathrm{s}}^{\mathrm{h}}$ he most common cause of primary headaches is migraine. Migraine is a type of chronic headache, presenting with attacks that last for hours to days and causes severe pain which is throbbing, usually unilateral and increases with head movements, interfering with everyday activities of patients. Migraine is about 3 times higher in women than in men $(15-20 \%$ in women and $6-10 \%$ in men). It mostly affects middle-aged people, less often teenagers and people over 60 years. While numerous factors have been investigated in the etiology of migraine, systemic inflammation is thought to have a big role in its pathophysiology ${ }^{[1-3]}$.

Correspondence (İletişim): Zeynep Bastuğ Gül, M.D. Saglik Bilimleri Universitesi, Noroloji Anabilim Dali, Bakirkoy Prof. Dr. Mazhar Osman Psikiyatri, Norolojik ve Norosirurji Hastaliklari Egitim ve Arastirma Hastanesi, İstanbul, Turkey

Phone (Telefon): +90 2124091515 E-mail (E-posta): drzeynep34@hotmail.com

Submitted Date (Başvuru Tarihi): 23.01.2021 Accepted Date (Kabul Tarihi): 30.03.2021

Copyright 2021 Haydarpaşa Numune Medical Journal

OPEN ACCESS This is an open access article under the CC BY-NC license (http://creativecommons.org/licenses/by-nc/4.0/) 
Erythrocyte sedimentation rate (ESR) and C-reactive protein (CRP) are the most commonly used inflammatory markers in clinical practice. Neurogenic inflammation triggers neuronal activation during migraine attacks, allowing the release of pro-inflammatory neuropeptides at perivascular neural endings. Inflammatory processes in vascular structure cause ischemic stroke $\mathrm{e}^{[4,5]}$. There are studies in literature showing that, CRP levels were considerably higher in patients with migraine, compared to control groups, supporting the role of neurogenic inflammation in migraine $^{[6,7]}$. Systemic inflammation and migraine were evaluated together and migraine was found to be associated with immunological and inflammatory pathways ${ }^{[1,2]}$.

The red blood cell distribution width (RDW) is a measure of size variability in red blood cells, while plateletcrit represents total platelet mass. RDW and platelecrit are inflammation-related parameters of complete blood count (CBC) examination. High RDW is recognized in the literature as associated with atherosclerosis, vascular occlusive diseases, inflammatory bowel disease, acute and chronic heart failure, atrial fibrillation, ischemic stroke, and many other inflammatory diseases ${ }^{[8-16]}$. The increase in RDW reflects the increase in other inflammation parameters in blood such as tumor necrosis factor alpha (TNF-a), hepcidin, and interleukin-6 (IL-6).

The parameters of $C B C, R D W$ in particular, have been investigated in many diseases; however, there are not enough studies on migraine. In this study, we evaluated inflammatory markers such as plateletcrit, RDW, ESR, and CRP to understand the role of inflammation in the pathophysiology of migraine.

\section{Materials and Methods}

In this study, 100 patients who were diagnosed with migraine according to the International Classification of Headache Disorders-3 criteria and 67 healthy controls with similar demographic characteristics who applied to our hospital between June 2019 and March 2020 were included in the study ${ }^{[17]}$. There were 74 patients without aura and 26 patients with aura. Patients were examined during interictal periods. After $12 \mathrm{~h}$ of fasting, venous blood samples were taken from patients for biochemical and CBC examinations. CBC (RDW, plateletcrit, WBC, neutrophils, lymphocytes, and platelets), ESR, CRP, fasting blood glucose, and serum creatinine were compared between these two groups. The neutrophil-lymphocyte ratio was calculated by dividing the absolute neutrophil count by the number of lymphocytes.
Patients having other types of headaches, other neurological diseases, those with infectious diseases or hematological diseases, in pregnancy or postpartum periods and under steroid treatment were not included in this study. The protocol of the study was approved by the institutional ethical committee (03.03.2020-421). The study was conducted in accordance with the Helsinki Declaration Principles.

\section{Statistical Analysis}

Demographic characteristics and laboratories were recorded in SPSS. Statistical analyses were performed in SPSS statistical software, version 17.0 (SPSS Inc., Chicago, IL, USA). Mean values (standard deviation) and \% (n) were reported for continuous and categorical variables, respectively. The comparison of parametric values between the two groups was made by the two-tailed Student's t test. Categorical was also compared to odds ratio with chi-sqaure or Fisher's exact tests. The Spearman correlation coefficient was calculated to compare the two data sets. For multivariate analysis, possible factors were identified by univariate analysis; further logistic over-regression analysis was performed to determine independent predictors of migraine. In the statistical evaluation, a value of $p<0.05$ was considered significant.

\section{Results}

In this study, 100 patients were included in the migraine group and 67 patients in the control group. The mean age was $40.97 \pm 12.00(18-68)$ in the migraine group and $41.19 \pm 12.2(18-64)$ in the control group. The groups were similar in terms of age and gender (Table 1).

In migraine group, the mean levels of ESR, platelet count, and RDW were significantly higher than control group $(p=0.044, p=0.024$, and $p=0.002$, respectively). The parameters such as ferritin, liver enzymes, hemoglobin, hemato$c r i t$, and serum creatinine were similar ( $p>0.05)$. Although CRP, neutrophil-to-lymphocyte ratio (NLR) and plateletcrit were found to be higher in migraine group, it was not statistically significant (Table 1).

The univariate and multivariate analysis were performed to determine the factors associated with migraine. In univariant analysis, ESR, platelet count, and RDW in migraine group were found to be significantly higher than control group ( $p=0.047, p=0.027$, and $p=0.003$, respectively). Among these values, RDW level was higher in migraine group than control group, independently ( $p=0.048$ ) (Table 2 ).

Correlation analysis between RDW and other parameters is shown in Table 3. A positive correlation was observed between migraine group and $\operatorname{RDW}(p=0.002, r=0.237)$. 
Table 2. Univariate and multivariate analysis for independent predictors of migraine

\begin{tabular}{lcccccc}
\hline & \multicolumn{3}{c}{ Univariate } & & \multicolumn{2}{c}{ Multivariate } \\
\cline { 2 - 7 } & OR & Cl & P & OR & Cl & P \\
\hline RDW & 1.593 & $1.167-2.173$ & 0.003 & 1.437 & $1.003-2.059$ & 0.048 \\
Platelet count & 1.006 & $1.001-1.012$ & 0.027 & 1.004 & $0.997-1.010$ & 0.291 \\
ESR & 1.034 & $1.001-1.068$ & 0.047 & 1.028 & $0.994-10.62$ & 0.117 \\
\hline
\end{tabular}

RDW: Red cell distribution width; ESR: Erythrocyte sedimentation rate; OR: Odds ratio; Cl: Confidence interval.

Table 1. Baseline characteristics of patients

\begin{tabular}{|c|c|c|c|}
\hline & $\begin{array}{l}\text { Migraine group } \\
\qquad(n=100)\end{array}$ & $\begin{array}{c}\text { Control group } \\
(n=67)\end{array}$ & $\mathbf{p}$ \\
\hline Age, years & $40.97 \pm 12.00$ & $41.19 \pm 12.20$ & 0.91 \\
\hline Male (n) (\%) & $20(20)$ & $16(24)$ & 0.55 \\
\hline Female (n) (\%) & $80(80)$ & $51(76)$ & \\
\hline White blood cell $\left(10^{3} / \mathrm{mm}^{3}\right)$ & 3) $7.29 \pm 1.90$ & $7.00 \pm 1.60$ & 0.30 \\
\hline Neutrophil $\left(10^{3} / \mathrm{mm}^{3}\right)$ & $4.31 \pm 1.55$ & $3.88 \pm 1.12$ & 0.056 \\
\hline Lymphocyte $\left(10^{3} / \mathrm{mm}^{3}\right)$ & $2.33 \pm 0.67$ & $2.37 \pm 0.72$ & 0.68 \\
\hline $\begin{array}{l}\text { Neurophil-to-lymphocyte } \\
\text { ratio (NLR) }\end{array}$ & $2.01 \pm 1.07$ & $1.79 \pm 0.78$ & 0.14 \\
\hline Platelet $\left(10^{3} / \mathrm{mm}^{3}\right)$ & $281.12 \pm 66.90$ & $259.57 \pm 48.11$ & 0.024 \\
\hline Plateletcrit (\%) & $0.28 \pm 0.06$ & $0.27 \pm 0.59$ & 0.10 \\
\hline RDW (\%) & $13.84 \pm 1.32$ & $13.24 \pm 0.98$ & 0.002 \\
\hline Glucose (mg/dL) & $98.36 \pm 17.83$ & $100.42 \pm 18.04$ & 0.47 \\
\hline Creatinine (mg/dL) & $0.68 \pm 0.12$ & $0.71 \pm 0.13$ & 0.1 \\
\hline $\operatorname{ESR}(\mathrm{mm} / \mathrm{h})$ & $16.91 \pm 11.65$ & $12.87 \pm 10.52$ & 0.044 \\
\hline $\mathrm{CRP}(\mathrm{mg} / \mathrm{dL})$ & $3.73 \pm 3.88$ & $2.96 \pm 3.22$ & 0.21 \\
\hline Ferritin (ng/mL) & $34.55 \pm 38.28$ & $38.00 \pm 46.31$ & 0.62 \\
\hline Hemoglobin (g/dL) & $13.28 \pm 1.47$ & $13.56 \pm 1.51$ & 0.23 \\
\hline Hematocrit (\%) & $40.40 \pm 3.78$ & $41.16 \pm 4.11$ & 0.22 \\
\hline AST (U/L) & $19.55 \pm 6.95$ & $21.15 \pm 6.38$ & 0.14 \\
\hline ALT (U/L) & $18.77 \pm 11.75$ & $21.98 \pm 11.86$ & 0.09 \\
\hline LDH (U/L) & $183.49 \pm 29.15$ & $193.33 \pm 33.78$ & 0.12 \\
\hline GGT (U/L) & $20.72 \pm 17.16$ & $22.89 \pm 18.05$ & 0.47 \\
\hline
\end{tabular}

Mean values (standart deviation) and $\%(\mathrm{n})$ were reported for continuous and categorical variables, respectively. RDW: Red cell distributation width, ESR: Erythrocyte sedimentation rate, CRP: C-reactive protein, ALT: Alanine transaminase, AST: Aspartate transaminase, LDH: Lactic acid dehydrogenase, GGT: Gamma-glutamyl transpeptidase. NLR: Neutrophilto-lymphocyte ratio.

Besides, positive correlation was defined between RDW and parameters such as neutrophil and platelet counts, plateletcrit, and CRP.

In a receiver operating characteristic curve analysis, an RDW value of $13.25 \%$ was identified as an effective cutoff point for migraine (area under curve $=0.620,95 \%$ confidence interval: $0.53-0.71, p=0.009$ ). An RDW value above $13.25 \%$ provided a specificity of $54 \%$ and a sensitivity of $58 \%$ (Fig. 1).
Table 3. Correlations analysis of red blood cell distribution width and other parameters

\begin{tabular}{lcc}
\hline & \multicolumn{2}{c}{ RDW } \\
\cline { 2 - 3 } & $\mathbf{r}$ & $\mathbf{P}$ \\
\hline Migraine group & 0.237 & 0.002 \\
Neutrophil count & 0.171 & 0.027 \\
Platelet count & 0.288 & $0.001<$ \\
Plateletcrit & 0.349 & $0.001<$ \\
CRP & 0.186 & 0.025 \\
\hline
\end{tabular}

CRP: C-reactive protein.

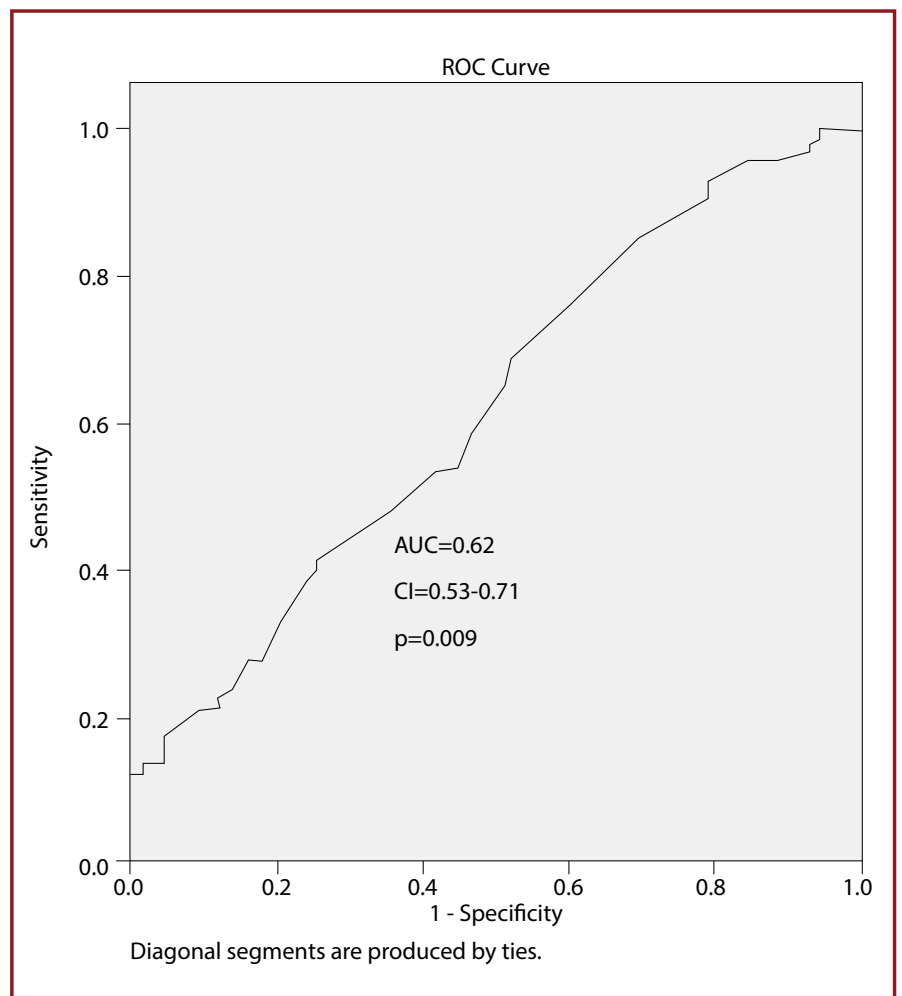

Figure 1. In a receiver operating characteristic curve analysis, an RDW value of $13.25 \%$ was identified as an effective cutoff point for migraine (area under curve $=0.620,95 \%$ Confidence interval: $0.53-$ $0.71, p=0.009$ ). An red blood cell distribution width value of more than $13.25 \%$ yielded a sensitivity of $58 \%$ and a specificity of $54 \%$. 


\section{Discussion}

Our study revealed that inflammation is involved in the pathophysiology of migraine. In our analysis, we found that RDW was higher in migraine patients than control group, independent of other variables. RDW values were also correlated with other inflammatory markers such as neutrophils, platelets, plateletcrit, and CRP.

In the literature, there are few studies on migraine with conflicting results, investigating similar pathophysiological mechanisms. In the study on 50 migraine and 40 control patients, RDW was found higher in migraine group, but other inflammatory markers were not studied, and multivariate analysis was not evaluated ${ }^{[18]}$. There are two other studies examining the relationship between RDW and migraine. Acar et al. compared patients with migraine and patients having non-specific headaches and revealed that migraine and NLR were correlated, whereas no relationship between migraine and RDW ${ }^{[19]}$. Celikbilek et al. ${ }^{[20]}$ compared migraine and control groups in their study and found that hemoglobin and hematocrit values were significantly lower in migraine group, and RDW was higher in migraine group. In our study, hemoglobin and hematocrit values were similar in both groups, regardless of these values, RDW was higher in migraine group. Moreover, the inflammatory markers such as CRP and ESR were also evaluated in our study; as a result, RDW was found higher in migraine group independent of other parameters. Our research supports that RDW is an independent predictor for migraineurs.

It has been clearly shown that the pathophysiology of migraine is strongly related to neurogenic inflammation ${ }^{[21]}$. In patients with migraine, inflammatory cytokines such as IL-6, TNF-a, and IL-10 are predicted to induce recurrent attacks by sensitizing nerve endings ${ }^{[22]}$. Several studies have identified the risks associated with the common pathophysiology of inflammatory arteriopathy in brain and cardiac vessels for migraine, ischemic cerebrovascular, and cardiogenic diseases ${ }^{[23,24]}$. CRP, one of the inflammatory markers, has also been reported to be a marker in migraine sufferers. In Tekesin et al's ${ }^{[2]}$ study, CRP and ESR values have been found to be high in migraine patients, as in our results.

RDW is a numerical value that indicates the diversity of the erythrocyte circulating cell type. RDW can be measured routinely as a part of automated CBC. Inflammatory cytokines and oxidative stress suppress bone marrow functions, causing the release of immature erythrocytes into circulation that affects RDW value. Consequently, these mechanisms including neurohormonal activation, chronic inflammatory state, and accelerated atherosclerotic process may contribute poor clinical outcomes ${ }^{[25,26]}$. A correlation has been established between increased RDW and inflammatory markers such as white blood cell count B-type natriuretic peptide and sedimentation rate ${ }^{[27]}$. High RDW has been associated with atherosclerosis, vascular occlusive diseases, inflammatory bowel disease, acute and chronic heart failure, atrial fibrillation, stroke, and other inflammatory diseases ${ }^{[8-16]}$. This is explained by the fact that RDW reflects the increase in inflammatory markers such as TNF- $a$, hepcidin, and IL- 6 in the blood. In our study, RDW values were significantly higher in migraine group than in control group, and it was observed that there was a correlation with inflammatory parameters such as neutrophil and platelet counts, plateletcrit, and CRP.

The plateletcrit is a part of the routine CBC examination and an indicator of total platelet mass. Platelets release many mediators such as thromboxanes that may lead to increase in inflammation. In patients with myocardial infarction, increased plateletcrit values at the admission have been reported to be independently associated with long-term poor outcomes ${ }^{[28]}$. The plateletcrit value in our study was higher compared to control group for migraine patients but it was not statistically significant.

NLR is a neutrophil/lymphocyte derivative of CBC examination, indicating inflammation ${ }^{[29]}$. In a study conducted in our country with 136 patients with migraine, NLR value was found higher in migraine patients than controls. In addition, NLR was reported to be associated with inflammatory processes in this study ${ }^{[2]}$. NLR was found high in migraine group in our study in accordance with the literature, but it was not found statistically significant.

The immune system and inflammation can play a role in migraine disease. In a study conducted in our country, CRP and the number of immune cells in the peripheral blood were evaluated in patients with migraine compared to controls ${ }^{[30]}$. As a result, increased peripheral inflammation levels were found in migraine disease, which may be associated with migraine neuroinflammation.

\section{Study Limitations}

First, our study was a single-center study and the number of patients was limited. The second limitation is IL-6, TNF-a, and other markers of oxidative stress are not assessed, because such inflammatory biomarkers are expensive and cannot be routinely used in daily practice. Third, it is known that higher RDW values are more common in anemic patients. In this study, although ferritin and hemoglobin levels were evaluated and were not associated with the high 
values of RDW in migraine group, iron levels or iron binding capacity were not investigated.

\section{Conclusion}

Inflammation plays an important role in the pathophysiology of migraine. RDW and other parameters of $\mathrm{CBC}$ are commonly and widely used tests in clinical practice. RDW may be an important independent predictor of migraine as an inflammatory marker.

\section{Source of Finance}

During this study, no financial or spiritual support was received neither from any pharmaceutical company that has a direct connection with the research subject, nor from a company that provides or produces medical instruments and materials which may negatively affect the evaluation process of this study.

Ethics Committee Approval: The protocol of the study was approved by the institutional ethical committee (03.03.2020-421). The study was conducted in accordance with the Helsinki Declaration Principles.

Peer-review: Externally peer-reviewed.

Authorship Contributions: Concept: Z.B.G., R.G.G.Ç.; Design: Z.B.G., R.G.G.Ç., A.S.; Data Collection or Processing: Z.B.G., B.S., S.A.; Analysis or Interpretation: Z.B.G., M.G., B.S.; Literature Search: Z.B.G., M.G., S.A.; Writing:Z.B.G., R.G.G.Ç., A.S.

Conflict of Interest: None declared.

Financial Disclosure: The authors declared that this study received no financial support.

\section{References}

1. Yazar HO, Yazar T, Aygün A, Kaygisiz Ş, Kirbaş D. Evaluation of simple inflammatory blood parameters in patients with migraine. Ir J Med Sci 2020;189:677-83. [CrossRef]

2. Tekeşin A, Tunç A. Evaluation of inflammatory markers in patients with migraine. Arch Clin Exp Med 2019;4:37-40.

3. Özcan RK, Özmen SG. The association between migraine, metabolic syndrome, insulin resistance, and obesity in women: $A$ case-control study. Sisli Etfal Hastan Tip Bul 2019;53:395-402.

4. Welch KM. Stroke and migraine--the spectrum of cause and effect. Funct Neurol 2003;18:121-6.

5. Lindsberg PJ, Grau AJ. Inflammation and infections as risk factors for ischemic stroke. Stroke 2003;34:2518-32. [CrossRef]

6. Lippi G, Mattiuzzi C, Cervellin G. C-reactive protein and migraine. Facts or speculations? Clin Chem Lab Med 2014;52:1265-72. [CrossRef]

7. Vanmolkot $\mathrm{FH}$, de Hoon JN. Increased C-reactive protein in young adult patients with migraine. Cephalalgia 2007;27:8436. [CrossRef]

8. Kalaycı B. The relationship between hemogram parameters and thrombolytic treatment success in patients with ST elevation myocardial infarction. MN Kardiyol 2018;25:115-20.

9. Hamur H, Kalkan K, Duman H, Durakoğlugil ME, Kuçuksu Z, Inci $S$, et al. Plateletcrit and platelet distribution width as independent predictors of coronary artery ectasia. Koşuyolu Heart J 2016;19:173-8. [CrossRef]

10. Gul M, Uyarel H, Ergelen M, Karacimen D, Ugur M, Turer A, et al. The relationship between red blood cell distribution width and the clinical outcomes in non-ST elevation myocardial infarction and unstable angina pectoris: A 3-year follow-up. Coron Artery Dis 2012;23:330-6. [CrossRef]

11. Uyarel H, Ergelen M, Cicek G, Kaya MG, Ayhan E, Turkkan C, et al. Red cell distribution width as a novel prognostic marker in patients undergoing primary angioplasty for acute myocardial infarction. Coron Artery Dis 2011;22:138-44. [CrossRef]

12. Felker GM, Allen LA, Pocock SJ, Shaw LK, McMurray JJ, Pfeffer MA, et al. Red cell distribution width as a novel prognostic marker in heart failure: Data from the CHARM Program and the Duke Databank. J Am Coll Cardiol 2007;50:40-7. [CrossRef]

13. Kara H, Degirmenci S, Bayir A, Ak A, Akinci M, Dogru A, et al. Red cell distribution width and neurological scoring systems in acute stroke patients. Neuropsychiatr Dis Treat 2015;11:733-9. [CrossRef]

14. Wen Y. High red blood cell distribution width is closely associated with risk of carotid artery atherosclerosis in patients with hypertension. Exp Clin Cardiol 2010;15:37-40.

15. Arhan M, Onal IK, Tas A, Kurt M, Kalkan IH, Özin Y, et al. The role of red cell distribution width as a marker in inflammatory bowel disease. Turk J Med Sci 2011;41:227-34.

16. Sarikaya S, Şahin Ş, Akyol L, Börekçi E, Yilmaz YK, Altunkaş F, et al. Is there any relationship between RDW levels and atrial fibrillation in hypertensive patient? Afr Health Sci 2014;14:26772. [CrossRef]

17. Headache classification committee of the international headache society (IHS) the international classification of headache disorders, 3rd edition. Cephalalgia 2018;38:1-211.

18. Bas FY, Demirci S, Arslan B. The relationship between headache features and haematological parameters in migraine patients. Euras J Fam Med 2015;4:53-6.

19. Acar E, Beydilli H, Karagöz U, Yildirim B, Kirli I, Kilinç RM, et al. Neutrophil-lymphocyte ratio can distinguish migraine patients from other patients with nonspecific headache in the emergency department. Acta Med Mediterr 2015;31:829-34.

20. Celikbilek A, Zararsiz G, Atalay T, Tanik N. Red cell distribution width in migraine. Int J Lab Hematol 2013;35:620-8. [CrossRef]

21. Spierings EL. Pathogenesis of the migraine attack. Clin J Pain 2003;19:255-62. [CrossRef]

22. Wang F, He Q, Ren Z, Li F, Chen W, Lin X, et al. Association of serum levels of intercellular adhesion molecule- 1 and interleukin-6 with migraine. Neurol Sci 2015;36:535-40. [CrossRef]

23. Yetkin E, Ozisik H, Ozcan C, Aksoy Y, Turhan H. Decreased endothelium-dependent vasodilatation in patients with migraine: A new aspect to vascular pathophysiology of migraine. Coron Artery Dis 2006;17:29-33. [CrossRef] 
24. Avci AY, Lakadamyali H, Arikan S, Benli US, Kilinc M. High sensitivity C-reactive protein and cerebral white matter hyperintensities on magnetic resonance imaging in migraine patients. J Headache Pain 2015;16:9. [CrossRef]

25. Pierce CN, Larson DF. Inflammatory cytokine inhibition of erythropoiesis in patients implanted with a mechanical circulatory assist device. Perfusion 2005;20:83-90. [CrossRef]

26. Kiefer CR, Snyder LM. Oxidation and erythrocyte senescence. Curr Opin Hematol 2000;7:113-6. [CrossRef]

27. Fukuta H, Ohte N, Mukai S, Saeki T, Asada K, Wakami K, et al. Elevated plasma levels of B-type natriuretic Peptide but not $\mathrm{C}$-reactive protein are associated with higher red cell distribu- tion width in patients with coronary artery disease. Int Heart J 2009;50:301-12. [CrossRef]

28. Gul M, Uyarel H, Akgul O, Akkaya E, Surgit O, Cakmak HA, et al. Long-term prognostic significance of admission plateletcrit values in patients with non-ST elevation myocardial infarction. Blood Coagul Fibrinolysis 2016;27:696-701. [CrossRef]

29. Núñez J, Núñez E, Bodí V, Sanchis J, Miñana G, Mainar L, et al. Usefulness of the neutrophil to lymphocyte ratio in predicting long-term mortality in ST segment elevation myocardial infarction. Am J Cardiol 2008;101:747-52. [CrossRef]

30. Avci AY, Akalin O. Migraine and peripheral inflammation. Acta Med Alanya 2017;1:20-7. 